\title{
Treatment of Primary Systemic Vasculitis with the Inosine Monophosphate Dehydrogenase Inhibitor Mycophenolic Acid
}

\author{
Thomas F. Hiemstra ${ }^{a}$ b Rachel B. Jones ${ }^{a}$ David R.W. Jayne ${ }^{a}$ \\ a Lupus and Vasculitis Unit, Addenbrookes Hospital, and b ${ }^{\mathrm{b}}$ Department of Medical Genetics, \\ University of Cambridge, Cambridge Institute for Medical Research, Cambridge, UK
}

\section{Key Words}

Antineutrophil cytoplasmic antibody $\cdot$ Mycophenolate mofetil $\cdot$ Mycophenolic acid $\cdot$ Toxicity $\cdot$ Vasculitis

\begin{abstract}
Despite advances in the treatment of vasculitis, modern therapies fail to induce or maintain remission in a significant proportion of patients. Mycophenolic acid is increasingly used to treat vasculitis syndromes. Here, we consider relevant pharmacokinetic and pharmacodynamic properties of mycophenolate, with emphasis on the impact of renal impairment, and we review the existing evidence for and current trials of mycophenolate in the treatment of primary systemic vasculitides.

Copyright $\odot 2010$ S. Karger AG, Base
\end{abstract}

\section{Background}

The introduction of cyclophosphamide and glucocorticoids dramatically changed the prognosis of antineutrophil cytoplasmic antibody (ANCA)-associated vasculitides from an almost invariably fatal disease to a controllable illness. Despite this, the toxicity and partial efficacy of modern treatments represent an unmet need for better therapies $[1,2]$.

\section{KARGER}

Fax +41613061234 E-Mail karger@karger.ch www.karger.com

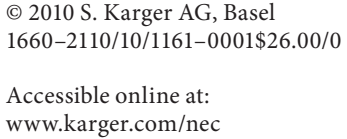

With standard therapy, up to $30 \%$ of patients fail to achieve complete remission. Of those who achieve complete remission, $50 \%$ experience a relapse within 5 years $[3,4]$. Relapse is associated with increased exposure to toxic immunosuppressant therapies and glucocorticoids which carry a high side effect burden and predispose to infection [5]. Of particular concern is the contribution of cyclophosphamide to the increased risk of malignancy seen in vasculitis and to infertility. Alternative therapies are clearly needed.

The past decade has seen the successful introduction of mycophenolate mofetil (MMF) as rejection prophylaxis in solid organ transplantation [6, 7], and its increasing use as therapy for autoimmune diseases $[8,9]$. In solid organ transplantation, MMF may be more effective than azathioprine in preventing acute rejection episodes $[6,10-13]$ or at least equally efficacious $[14,15]$, and prolongs graft survival when compared to azathioprine [16]. As azathioprine is the standard remission-maintaining drug in renal vasculitis, comparison to azathioprine in other scenarios are valid. In lupus nephritis, the MAINTAIN trial compared MMF to azathioprine after remission induction with cyclophosphamide, and found no difference in rates of relapse between groups [17]. Randomized trial evidence in lupus suggests that MMF is equivalent to cyclophosphamide for remission induction [18-22] and has been successful where other therapies

Tel. +44 1223217 259, Fax +44 1223586 506, E-Mail dj106@ cam.ac.uk 
Fig. 1. In activated lymphocytes, the activity of IMPDH increases by tenfold. Lymphocytes are uniquely dependent on this pathway for DNA synthesis, whereas guanine monophosphate may be synthesized by a salvage pathway in other cells. For this reason, MMF specifically inhibits proliferation of B and T lymphocytes. Adapted from Stepkowski [79].

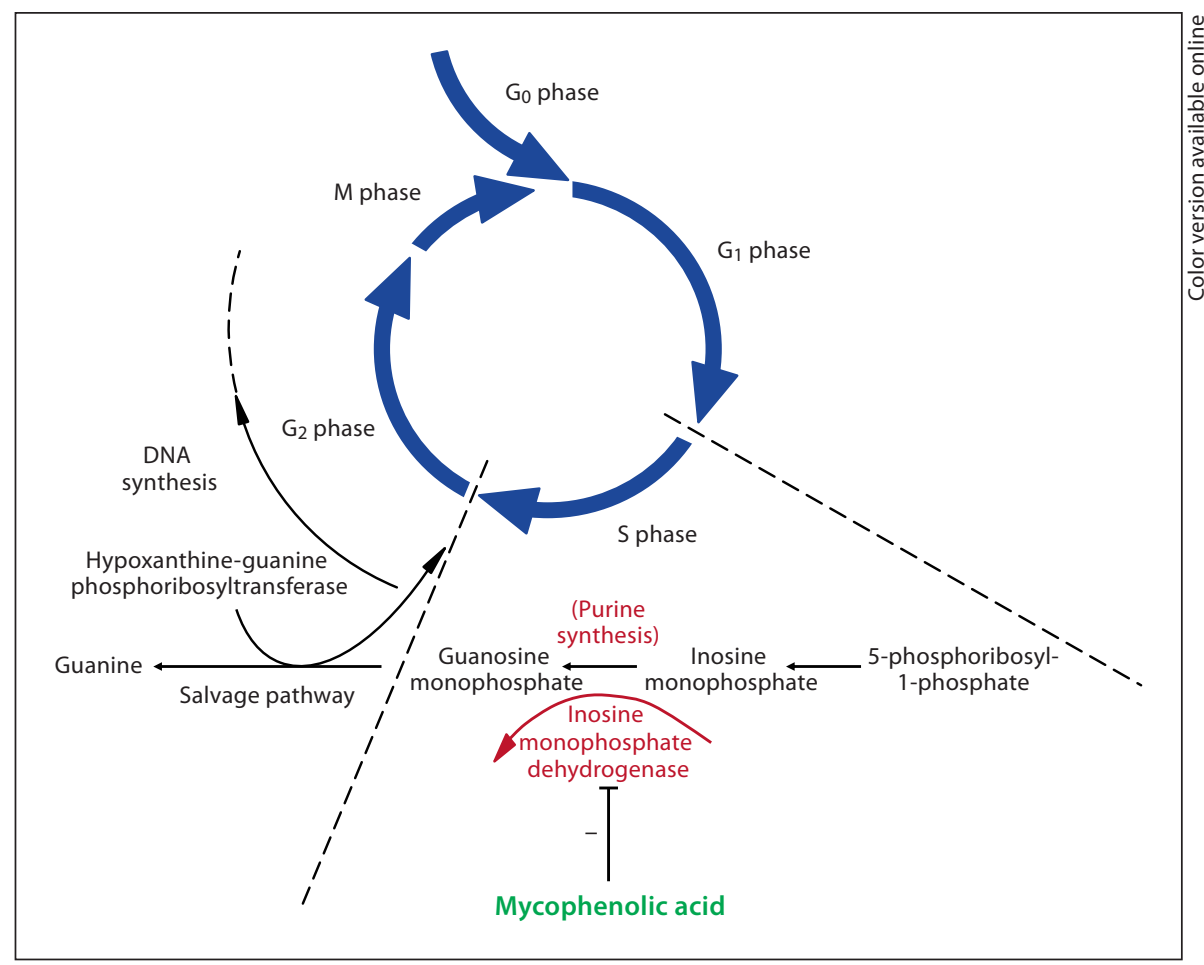

have failed [23, 24]. Walsh et al. [25] reported a lower rate of remission failures with MMF compared to cyclophosphamide in a meta-analysis of 4 randomized trials comprising 268 patients, and a recent large randomized trial of 370 patients reported similar response rates when MMF was compared with cyclophosphamide as induction therapy [26]. A clear rationale therefore exists for the evaluation of MMF in the treatment of vasculitis. This review considers the role of mycophenolate in vasculitis syndromes, focusing largely on the ANCA-associated vasculitides.

\section{Mycophenolic Acid}

Mycophenolic acid (MPA) was first isolated from Penicillium brevicompactum by Gozio [27] in 1896, and subsequently given its name in 1913 by Alsberg and Black [28]. As MPA causes severe gastrointestinal side effects when administered by mouth, it is most commonly administered as a prodrug, MMF $\left(\right.$ Cellcept $\left.^{\circledR}\right)$, or as enteric coated mycophenolate sodium (Myfortic ${ }^{\circledR}$ ).

MMF is a morpholinoethyl ester of MPA, to which it is converted in the liver. MPA in turn noncompetitively and reversibly inhibits types I and II inosine monophos- phate dehydrogenase (IMPDH) activity during DNA synthesis in the S phase of the cell cycle [29], preventing guanine monophosphate synthesis (fig. 1). T and B lymphocytes are uniquely dependent on the de novo synthesis of guanosine nucleotides, unlike other cell types, which are able to utilize a salvage synthesis pathway. MMF is therefore considered relatively lymphocyte selective compared to other purine antagonists such as azathioprine. In addition to this 'conventional' mechanism of action, MMF may also inhibit the migration of monocytes to and adhesion of activated lymphocytes at the site of inflammation [30, 31].

\section{Pharmacokinetics and the Effects of Renal Impairment}

After oral administration, MMF is almost completely absorbed and rapidly converted to MPA by hepatic ester hydrolysis. Accordingly, MMF levels fall below detectable blood limits within $10 \mathrm{~min}$ of oral administration $[32,33]$, and the plasma concentration of MPA peaks after $1 \mathrm{~h}$. After mycophenolate sodium administration, plasma MPA peaks later, after $2 \mathrm{~h}$, though pharmacokinetic properties are otherwise similar to MMF. 
MPA is more than $97 \%$ protein bound [33], and undergoes phase II metabolism by hepatic and, to a lesser extent, intestinal and renal glucuronidation by several uridine- $\gamma$-transferase (UGT) enzyme isoforms. The predominant glucuronidation product is MPA 7-O-glucuronide (MPAG). MPAG is not pharmacologically active [32], is filtered by the glomerulus and actively secreted by renal tubular cells, and thus largely excreted by the kidney [33]. However, MPAG undergoes enterohepatic recirculation and is deglucuronidated to MPA in the intestine and reabsorbed, accounting for a second MPA peak in plasma 8-12 h after MMF administration. Importantly, MPAG is also highly protein bound and displaces MPA from albumin (fig. 2).

MPA is also glucuronidated to its acyl-glucuronide (AcMPAG) which, like MPAG, is excreted by the kidneys [34]. AcMPAG is also a metabolic product of other carboxylic drugs such as ibuprofen and diclofenac [35], and has been associated with their toxic effects [36]. AcMPAG is pharmacologically active, inhibiting IMPDH-II in vitro with similar efficacy to MPA [37].

The influence of impaired renal function on MPA exposure and hence toxicity is controversial. Although an early report on pharmacokinetics indicated that MPA exposure was independent of renal function [38], an inverse relationship between allograft function and MPA levels has been described in renal transplant recipients [39]. The area under the curve (AUC) for both MPAG and AcMPAG is increased in renal impairment, and trough- and pre-dose levels of AcMPAG are significantly higher in patients with renal impairment [36]. MacPhee et al. [40] reported MPAG accumulation and a marked increase in the MPAG AUC in dialysis patients. Renal impairment may therefore lead to increased toxicity by three distinct mechanisms: (1) MPAG accumulation displaces MPA from albumin, thereby increasing serum concentration; (2) MPAG accumulation gives rise to increased MPA formation by MPAG deglucuronidation, and (3) decreased clearance of AcMPAG may be associated with direct toxicity. Uremic subjects may also have higher MPA exposure due to inhibition of UGT by uremic toxins [41].

\section{Trough Level Monitoring}

MPA trough level monitoring (TLM) has received considerable interest in transplantation and, more recently, in autoimmunity. Following MMF administration MPA AUC measurements show marked inter-indi-

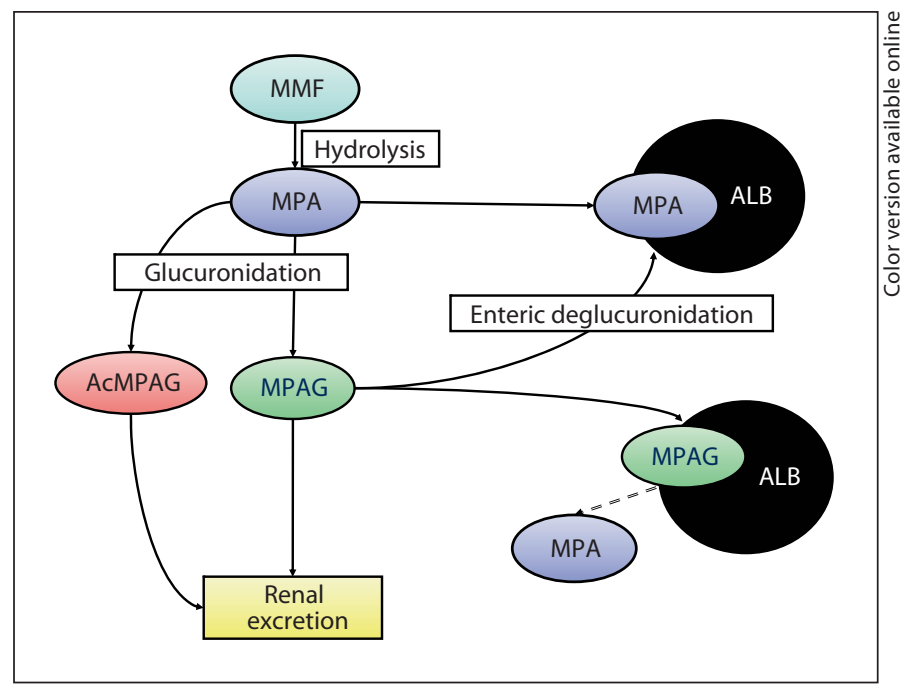

Fig. 2. MMF is rapidly hydrolyzed to MPA, which peaks in plasma $1 \mathrm{~h}$ after administration and is $80 \%$ albumin-bound. MPA undergoes enterohepatic recirculation. It is glucuronidated by the liver, and to a lesser extent, intestine and kidneys, to MPAG and AcMPAG. MPAG is resecreted into the intestine where it is deglucuronidated to MPA and reabsorbed, accounting for a second plasma MPA peak after 8-12 h. Both MPAG and AcMPAG are renally excreted and, in renal impairment, can reach sufficient concentrations in plasma to displace MPA from albumin.

vidual variation, which may owe to genetic polymorphisms of UGT enzymes, variations in serum albumin levels or renal function, or the use of concomitant therapies such as cyclosporine that influence enterohepatic MPA recirculation. The validity of fixed dosing for MMF has therefore been questioned.

Several studies in renal transplantation have reported improved outcomes with MPA TLM or AUC estimation $[42,43]$, although studies in this field are confounded by the concomitant use of other immune modulators that impact on MPA metabolism (e.g. cyclosporine). Two prospective randomized studies have compared dosing by TLM to fixed dose prescribing. The Adaption de Posologie du MMF en Greffe Renale (APOMYGRE) study reported significantly fewer treatment failures (defined as a composite endpoint of death, graft loss, acute rejection or MMF withdrawal) in the TLM adjusted group [44]. In contrast, the much larger Fixed Dose versus Concentration Controlled study enrolled 901 patients and reported a negative outcome despite a very similar design to APOMYGRE [45]. MPA TLM has not been shown to be cost effective to date [46], and the clinical utility of TLM remains unclear [47]. 
Table 1. Published studies on the use of MMF for the treatment of ANCA-associated vasculitis

\begin{tabular}{|c|c|c|c|c|c|}
\hline Langford [59] & Original article, uncontrolled, retrospective & AASV & NR & 2,000 & No \\
\hline Stassen $[54]$ & Original article, uncontrolled, retrospective & AASV & NR & 2,000 & No \\
\hline $\mathrm{Hu}[51]$ & Original article, randomized, prospective & AASV & NR & 2,000 & Yes \\
\hline Joy $[55]$ & Original article, uncontrolled, retrospective & AASV & NR (target 2,000) & 1,000 & No \\
\hline Nowack [56] & Original article, uncontrolled, retrospective & AASV & NR & 2,000 & No \\
\hline Yalcindag [80] & Original article, uncontrolled, retrospective & Ocular AASV & & 2,000 & No \\
\hline Iatrou $[81]$ & Original article, uncontrolled, retrospective & AASV & NR & & No \\
\hline
\end{tabular}

$\mathrm{MMF}=$ Mycophenolate mofetil; TTR = time to remission; $\mathrm{CR}=$ complete remission; $\mathrm{PR}=$ partial remission; $\mathrm{NR}=$ not reported; $\mathrm{NA}=$ not available.

Current evidence suggests important pharmacokinetic differences in autoimmune diseases such as ANCAassociated systemic vasculitis (AASV) and systemic lupus erythematosus (SLE) compared with solid organ transplantation. In autoimmune disease, both 12- and 24-hour MPA trough levels correlate with AUC [48] after the administration of MMF, making TLM clinically feasible. A recent small study including 10 patients with AASV and 6 patients with SLE suggested maintaining MPA 12-hour trough levels between 3.5 and 4.5 may be associated with better disease control and fewer adverse events [49]. Schaier et al. [50] reported a correlation of disease activity with low MPA trough levels in patients with AASV. However, both these studies were small, uncontrolled and recorded an insufficient number of events to draw firm conclusions. Prospective data to support the routine use of MPA TLM in autoimmune disease are lacking.

\section{Mycophenolate in AASV}

AASV remains the best studied of the primary systemic vasculitides. A number of groups have reported the use of MMF as induction and maintenance therapy for AASV. When interpreting the existing literature, the reader should consider that as with most new therapies, mycophenolate was initially used almost exclusively as salvage therapy for refractory disease or where other therapies had failed to maintain remission.

\section{Remission Induction}

Only one prospective randomized study evaluating the efficacy of mycophenolate in the treatment of AASV has been published to date [51]. In this study, 35 Chinese patients carrying a new diagnosis of AASV with renal involvement were assigned to receive MMF or cyclophosphamide, along with glucocorticoids, for remission induction. Eighteen patients were treated with MMF, all but one of whom had microscopic polyangiitis. Fourteen of 18 patients achieved remission after 6 months, compared to 8 of 13 patients in the cyclophosphamide group. Adverse event rates were similar between groups, and renal function at 6 months was not significantly different. Although this small study suggested the equivalence of mycophenolate to cyclophosphamide for remission induction, it has several important limitations: (1) the dose of cyclophosphamide used was low compared with other studies [52, 53]; (2) only 1 patient in the MMF group carried a diagnosis of Wegener's granulomatosis; (3) there was a high dropout rate in the cyclophosphamide arm; (4) the study population was exclusively Chinese, and (5) the study was not adequately powered to address the endpoint of induction failure. These results should therefore be interpreted with caution.

A number of uncontrolled series have reported mixed results after induction with MMF. Stassen et al. [54] reported complete remission in 25 of 32 patients with AASV, and partial remission in 6 patients. Only 1 patient failed to achieve remission [54], however an earlier series by Joy et al. [55] reported remission in only 7 of 12 pa- 


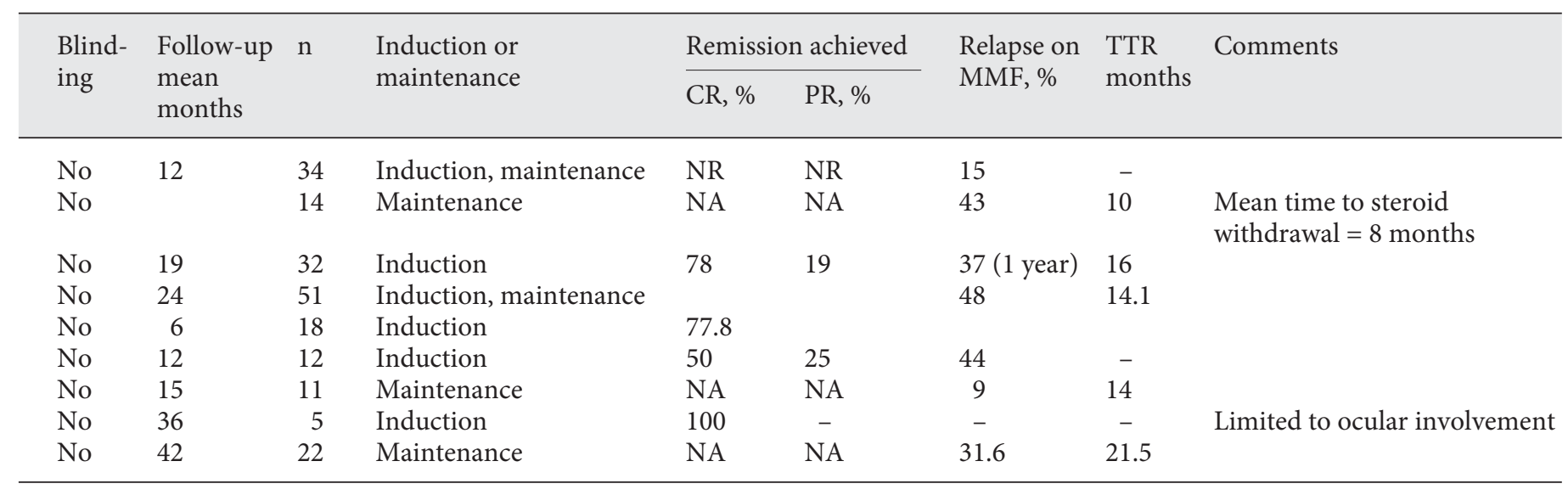

tients with AASV after 6 months. Current evidence is insufficient to support the routine use of mycophenolate for remission induction. A prospective randomized trial comparing MMF to cyclophosphamide (MYCYC) is currently recruiting (ISRCTN83027184; www.vasculitis. org), and will further assess the efficacy and safety of MMF as induction therapy.

\section{Remission Maintenance}

Mycophenolate has also been used as remission maintenance therapy in AASV. An initial uncontrolled pilot study in 11 patients with AASV evaluated MMF as maintenance therapy after conventional induction therapy with cyclophosphamide and glucocorticoids [56]. One patient experienced a relapse during 14 months of follow-up. As others have reported a mean time to relapse in AASV of 15 months [53], the duration of this study was short when considering relapse as the primary outcome.

More recently Kazderova et al. [57] reported the use of MMF in a cohort of 34 patients with glomerulonephritis due to AASV in a retrospective analysis. MMF was used either as induction therapy or as remission maintenance therapy, and proteinuria and serum creatinine were used as surrogates for disease activity. Although MMF was effective in preventing relapse in most patients, there was a high number of treatment withdrawals due to adverse events, the majority due to gastrointestinal side effects. By 6 months, 11 patients (32\%) had already withdrawn from treatment with MMF, 6 due to relapse. Nevertheless, in those patients where MMF was tolerated, creatinine stabilized and proteinuria reduced in the majority of patients. This study is weakened by its retrospective nature, the heterogeneity of the study population, and the lack of data to assess conventional measures of diseases activity. In another retrospective series of 51 patients with AASV, 29/51 patients received MMF as remission maintenance [58]. Fourteen of 29 patients (48\%) experienced relapse with a mean follow-up of 20 months. The remainder received MMF for induction for relapsing disease and were subsequently maintained on MMF. Of these, 19 of 22 achieved remission although 9 subsequently relapsed during follow-up. Taken together, this represents an almost 50\% relapse rate with a mean time to relapse of 14 months. Although this was relatively high, the mean dose of MMF in this cohort was $1.6 \mathrm{~g} / \mathrm{day}$, and this series included patients who had previously failed on other therapies. Langford et al. [59] studied 14 patients with Wegener's granulomatosis in whom MMF was used for maintenance after conventional induction therapy with cyclophosphamide and glucocorticoids, and also reported a high relapse rate $(43.8 \%$ with a mean time to relapse of 10 months). However in this series the mean time to steroid withdrawal was only 8 months. Similar to the report by Koukoulaki and Jayne [58], the relapse rate did not remain constant but increased with time as steroid therapy was withdrawn.

The International Mycophenolate Protocol to Reduce Outbreaks of Vasculitides randomized trial (IMPROVE, 
ISRCTN83027184; www.vasculitis.org) compared MMF to azathioprine after conventional induction therapy with cyclophosphamide and steroids. IMPROVE aimed to evaluate the efficacy and safety of MMF for remission maintenance in a large cohort $(n=175)$ of patients with AASV, and publication is anticipated during 2010.

Although the Churg-Strauss syndrome is also classed as an AASV, all randomized trials of AASV to date have excluded Churg-Strauss syndrome. Anecdotal reports indicate that mycophenolate has been used successfully in its treatment [60].

\section{Large Vessel Vasculitis}

The large vessel vasculitides include Takayasu's arteritis (TA) and giant cell arteritis. As with AASV, glucocorticoids are a mainstay therapy. Although glucocorticoids are efficacious, many patients require high doses to control disease, predisposing to glucocorticoid side effects [61]. More than half of patients with TA require the addition of an immunosuppressive agent to control disease and of these, only one third demonstrate a response to therapy [62].

There are only a small number of reports on the use of MMF in TA. Daina et al. [63] reported success with MMF in 3 TA patients with steroid-dependent disease. Two patients had previously received treatment with cytotoxic agents. MMF successfully reduced disease activity and steroid dependence in all 3 patients. Conversely, in a series of 15 patients with TA treated with anti-TNF $\alpha$ therapy, Hoffman and Ahmed [61] reported that MMF had previously failed to control disease in 3 patients. In an open label prospective study, Shinjo et al. [64] treated 13 patients with TA with MMF for a mean duration of 23.3 months. The addition of MMF to glucocorticoid therapy was successful in inducing remission in $12 / 13$ patients, and the remaining patient discontinued therapy due to drug intolerance.

\section{Other Vasculitis Syndromes}

Anecdotal evidence supports the use of MMF in a variety of vasculitic syndromes, including hypocomplementemic urticarial vasculitis [65], nodular vasculitis [66] and essential mixed cryoglobulinemia [67]. However, a study of the use of MMF as therapy for Behçet's disease was terminated prematurely due to lack of efficacy in the first 6 patients [68].

\section{Pregnancy and Lactation}

A review by the manufacturer of MMF identified 119 pregnancies with maternal fetal MMF exposure [69]. In this analysis only $34 \%$ of the 65 pregnancies for which the outcome was known resulted in healthy live births. Of the remainder, there were $20 \%$ elective terminations, $31 \%$ miscarriages, and $15 \%$ fetal abnormalities. These findings are congruent with a report by Sifontis et al. [70] on MMF exposure in 18 renal transplant recipients who had 26 pregnancies resulting in 11 spontaneous abortions and 15 live births. Four of the live births manifested structural malformations including microtia, cleft lip and palate, short fingers and nail hypoplasia, and 1 neonatal death with multiple abnormalities. Similar abnormalities have also been described by other authors [71, 72], leading to the recent proposal of a characteristic phenotype of mycophenolate embryopathy comprising cleft lip and palate and microtia [73].

MMF should therefore be avoided in patients actively attempting to conceive, and should not be administered during pregnancy. Women of childbearing age should have a negative pregnancy test prior to commencing treatment with MMF, and should receive contraceptive counseling. Mycophenolate is excreted in breast milk, and its use should be avoided in lactating women.

\section{Pediatric Practice}

There are few available data on the use of MMF in children with autoimmune diseases. In solid organ transplantation, MMF does appear to be safe in pediatric use. Jungraithmayr et al. [74] studied 83 pediatric and adolescent renal transplant recipients followed for 3 years, and reported infection rates similar to those in adults, with no other adverse effects to those documented in adult patients.

\section{Mycophenolate and Renal Fibrosis}

A large body of experimental evidence suggests an inhibitory effect of MMF on renal fibrosis. As reviewed by Morath et al. [75], MMF abrogates progression of renal disease in the 5/6th nephrectomy model of chronic renal impairment, reduces glomerulosclerosis, improves renal function, prevents the onset of proteinuria, and ameliorates cyclosporine-induced arteriolopathy, and at the molecular level reduces the expression of adhesion molecules CD18 and CD11b and other pro-fibrotic molecules. 
In man, MMF reduces circulating TGF- $\beta 1$ and tubular TGF- $\beta 1$, and IL- 6 expression in renal transplant recipients [75]. Furthermore, MMF reduces epithelial to mesenchymal transformation to an extent rivaled only by sirolimus but not by azathioprine, calcineurin inhibitors or glucocorticoids [76]. Transferring these data to the clinical arena, Nankivell et al. [77] recently reported a protective effect of MMF against renal fibrosis compared to azathioprine in renal transplant recipients treated with calcineurin inhibitors. In AASV with renal involvement, Hu et al. [51] suggested that MMF may be superior to intravenous cyclophosphamide in reducing proteinuria and improving renal function. The results of the MYCYC and IMPROVE trials should elucidate whether treatment with mycophenolate will lead to superior long-term renal outcomes compared to conventional therapy.

\section{Conclusion}

Mycophenolate is an attractive alternative to conventional induction therapy with cyclophosphamide for vasculitis as it is not associated with infertility or bladder carcinoma, and does not require intravenous administration. The hope exists that mycophenolate will provide su- perior efficacy with comparable or reduced toxicity compared to existing remission maintenance therapies. MMF will be off patent in 2011 but currently remains expensive, costing around ten times more than azathioprine in the United Kingdom.

MPA is now an established immunosuppressant in solid organ transplantation. Despite promising early pilot data in AASV, results from uncontrolled studies have been conflicting, and randomized trial data in vasculitis are still lacking. Furthermore, no adequately powered prospective studies of MMF in vasculitis have considered MPA level monitoring, and it is unknown whether level monitoring will improve efficacy and limit toxicity in autoimmune diseases including vasculitis. Level monitoring may be particularly important in patients with renal impairment. The ALMS study used MMF dosed at $3 \mathrm{~g} /$ day for lupus nephritis, and it is notable that there was no safety benefit of MMF over cyclophosphamide after 6 months [26]. ALMS did not employ level monitoring.

Based on current evidence and pending results from randomized studies, standard treatment guidelines for remission induction and maintenance therapy should apply [78]. Treatment with mycophenolate should be reserved for patients with refractory disease, or where conventional therapies are contraindicated.

\section{References}

1 Walton EW: Giant-cell granuloma of the respiratory tract (Wegener's granulomatosis). Br Med J 1958;ii:265-270.

$\checkmark 2$ Hiemstra TF, Jayne D: Newer therapies for vasculitis. Best Pract Res Clin Rheumatol 2009;23:379-389.

- 3 Pagnoux C, Mahr A, Hamidou MA, Boffa JJ, Ruivard M, Ducroix JP, Kyndt X, Lifermann F, Papo T, Lambert M, Le Noach J, Khellaf M, Merrien D, Puechal X, Vinzio S, Cohen P, Mouthon L, Cordier JF, Guillevin L: Azathioprine or methotrexate maintenance for ANCA-associated vasculitis. N Engl J Med 2008;359:2790-2803.

4 Booth AD, Almond MK, Burns A, Ellis P, Gaskin G, Neild GH, Plaisance M, Pusey CD, Jayne DR: Outcome of ANCA-associated renal vasculitis: a 5-year retrospective study. Am J Kidney Dis 2003;41:776-784.

-5 Bosch X, Guilabert A, Espinosa G, Mirapeix E: Treatment of antineutrophil cytoplasmic antibody associated vasculitis: a systematic review. JAMA 2007;298:655-669.
6 Placebo-controlled study of mycophenolate mofetil combined with cyclosporin and corticosteroids for prevention of acute rejection. European Mycophenolate Mofetil Cooperative Study Group. Lancet 1995;345:13211325.

7 Ekberg H, Bernasconi C, Tedesco-Silva $\mathrm{H}$ Vitko S, Hugo C, Demirbas A, Acevedo RR, Grinyo J, Frei U, Vanrenterghem Y, Daloze P, Halloran P: Calcineurin inhibitor minimization in the symphony study: observational results 3 years after transplantation. Am J Transplant 2009;9:1876-1885.

8 Karim MY, Alba P, Cuadrado MJ, Abbs IC, D'Cruz DP, Khamashta MA, Hughes GR: Mycophenolate mofetil for systemic lupus erythematosus refractory to other immunosuppressive agents. Rheumatology (Oxford) 2002;41:876-882.

-9 Fickert P, Hinterleitner TA, Wenzl HH, Aichbichler BW, Petritsch W: Mycophenolate mofetil in patients with Crohn's disease. Am J Gastroenterol 1998;93:2529-2532.

10 Sollinger HW: Mycophenolate mofetil for the prevention of acute rejection in primary cadaveric renal allograft recipients. U.S. Renal Transplant Mycophenolate Mofetil Study Group. Transplantation 1995;60:225-232.
11 Lang P, Pardon A, Audard V: Long-term benefit of mycophenolate mofetil in renal transplantation. Transplantation 2005; 79:S47-S48.

12 A blinded, randomized clinical trial of mycophenolate mofetil for the prevention of acute rejection in cadaveric renal transplantation. The Tricontinental Mycophenolate Mofetil Renal Transplantation Study Group. Transplantation 1996;61:1029-1037.

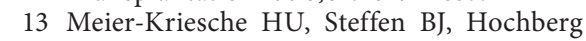
AM, Gordon RD, Liebman MN, Morris JA, Kaplan B: Long-term use of mycophenolate mofetil is associated with a reduction in the incidence and risk of late rejection. Am J Transplant 2003;3:68-73.

14 Burke GW 3rd, Kaufman DB, Millis JM, Gaber AO, Johnson CP, Sutherland DE, Punch JD, Kahan BD, Schweitzer E, Langnas A, Perkins J, Scandling J, Concepcion W, Stegall MD, Schulak JA, Gores PF, Benedetti E, Danovitch G, Henning AK, Bartucci MR, Smith S, Fitzsimmons WE: Prospective, randomized trial of the effect of antibody induction in simultaneous pancreas and kidney transplantation: three-year results. Transplantation 2004;77:1269-1275. 
15 Remuzzi G, Cravedi P, Costantini M, Lesti M, Ganeva M, Gherardi G, Ene-Iordache B, Gotti E, Donati D, Salvadori M, Sandrini S, Segoloni G, Federico S, Rigotti P, Sparacino V, Ruggenenti P: Mycophenolate mofetil versus azathioprine for prevention of chronic allograft dysfunction in renal transplantation: the MYSS follow-up randomized, controlled clinical trial. J Am Soc Nephrol 2007; 18:1973-1985.

- 16 Kainz A, Heinze G, Korbely R, Schwarz C, Oberbauer R: Mycophenolate mofetil use is associated with prolonged graft survival after kidney transplantation. Transplantation 2009;88:1095-1100.

17 Houssiau FA, D'Cruz DP, Sangle SR, Remy P, Vasconcelos C, Garrido E, Gilboe Sr IM, Ravelingien I, Tektonidou M, Depresseux G, Guillevin LP, Cervera R: Azathioprine versus mycophenolate mofetil for maintenance immunosuppression of proliferative lupus nephritis: results of a randomized trial (MAINTAIN). ACR Abstract. Arthritis Rheum 2009;60(suppl):1150.

-18 Chan TM, Li FK, Tang CS, Wong RW, Fang GX, Ji YL, Lau CS, Wong AK, Tong MK, Chan KW, Lai KN: Efficacy of mycophenolate mofetil in patients with diffuse proliferative lupus nephritis. Hong Kong-Guangzhou Nephrology Study Group. N Engl J Med 2000;343:1156-1162.

-19 Chan TM, Tse KC, Tang CS, Mok MY, Li FK: Long-term study of mycophenolate mofetil as continuous induction and maintenance treatment for diffuse proliferative lupus nephritis. J Am Soc Nephrol 2005;16:10761084.

20 Ong LM, Hooi LS, Lim TO, Goh BL, Ahmad G, Ghazalli R, Teo SM, Wong HS, Tan SY, Shaariah W, Tan CC, Morad Z: Randomized controlled trial of pulse intravenous cyclophosphamide versus mycophenolate mofetil in the induction therapy of proliferative lupus nephritis. Nephrology (Carlton) 2005; 10:504-510.

-21 Ginzler EM, Dooley MA, Aranow C, Kim MY, Buyon J, Merrill JT, Petri M, Gilkeson GS, Wallace DJ, Weisman MH, Appel GB: Mycophenolate mofetil or intravenous cyclophosphamide for lupus nephritis. N Engl J Med 2005;353:2219-2228.

22 Flores-Suarez LF, Villa AR: Open randomized trial comparing mycophenolate mofetil versus intravenous cyclophosphamide as induction therapy for severe lupus nephritis. J Am Soc Nephrol 2004; 15:PO257.

23 Glicklich D, Acharya A: Mycophenolate mofetil therapy for lupus nephritis refracto ry to intravenous cyclophosphamide. Am J Kidney Dis 1998;32:318-322.

-24 Briggs WA, Choi MJ, Scheel PJ Jr: Successful mycophenolate mofetil treatment of glomerular disease. Am J Kidney Dis 1998;31:213217.

-25 Walsh M, James M, Jayne D, Tonelli M, Manns BJ, Hemmelgarn BR: Mycophenolate mofetil for induction therapy of lupus nephritis: a systematic review and metaanalysis. Clin J Am Soc Nephrol 2007;2: 968-975.
-26 Appel GB, Contreras G, Dooley MA, Ginzler EM, Isenberg D, Jayne D, Li LS, Mysler E, Sanchez-Guerrero J, Solomons N, Wofsy D: Mycophenolate mofetil versus cyclophosphamide for induction treatment of lupus nephritis. J Am Soc Nephrol 2009;20:11031112.

27 Gozio B: Richerche bacteriologiche e chimiche sulle alterazoni del mais. Riv Igiene Sanita Pubbl Ann 1896;7:825.

28 Alsberg CL, Black OF: Contributions to the study of maize deterioration; biochemical and toxicological investigations of Penicillium puberulum and Penicillium stoloniferum. Bull US Bur Pl Ind 1913;270:7.

29 Sollinger HW, Deierhoi MH, Belzer FO, Diethelm AG, Kauffman RS: RS-61443 - a phase I clinical trial and pilot rescue study. Transplantation 1992;53:428-432.

30 Van Bruggen MC, Walgreen B, Rijke TP, Berden JH: Attenuation of murine lupus nephritis by mycophenolate mofetil. J Am Soc Nephrol 1998;9:1407-1415.

31 Heemann U, Azuma H, Hamar P, Schmid C, Tilney N, Philipp T: Mycophenolate mofetil inhibits lymphocyte binding and the upregulation of adhesion molecules in acute rejection of rat kidney allografts. Transplant Immunol 1996;4:64-67.

32 Lipsky JJ: Mycophenolate mofetil. Lancet 1996;348:1357-1359.

-33 Bullingham RE, Nicholls AJ, Kamm BR: Clinical pharmacokinetics of mycophenolate mofetil. Clin Pharmacokinet 1998;34: 429-455.

34 Shipkova M, Armstrong VW, Wieland E, Niedmann PD, Schutz E, Brenner-Weiss G Voihsel M, Braun F, Oellerich M: Identification of glucoside and carboxyl-linked glucuronide conjugates of mycophenolic acid in plasma of transplant recipients treated with mycophenolate mofetil. Br J Pharmacol 1999;126:1075-1082.

35 Shipkova M, Armstrong VW, Weber L, Niedmann PD, Wieland E, Haley J, Tonshoff B, Oellerich M: Pharmacokinetics and protein adduct formation of the pharmacologically active acyl glucuronide metabolite of mycophenolic acid in pediatric renal transplant recipients. Ther Drug Monit 2002;24 390-399.

36 Gonzalez-Roncero FM, Govantes MA, Chaves VC, Palomo PP, Serra MB: Influence of renal insufficiency on pharmacokinetics of acyl-glucuronide metabolite of mycophenolic acid in renal transplant patients. Transplant Proc 2007;39:2176-2178.

37 Shipkova M, Wieland E, Schutz E, Wiese C, Niedmann PD, Oellerich M, Armstrong VW: The acyl glucuronide metabolite of mycophenolic acid inhibits the proliferation of human mononuclear leukocytes. Transplant Proc 2001;33:1080-1081.

38 Johnson HJ, Swan SK, Heim-Duthoy KL, Nicholls AJ, Tsina I, Tarnowski T: The pharmacokinetics of a single oral dose of mycophenolate mofetil in patients with varying degrees of renal function. Clin Pharmacol Ther 1998;63:512-518.
39 Naesens M, de Loor H, Vanrenterghem Y, Kuypers DR: The impact of renal allograft function on exposure and elimination of mycophenolic acid (MPA) and its metabolite MPA 7-O-glucuronide. Transplantation 2007;84:362-373.

40 MacPhee IA, Spreafico S, Bewick M, Davis C, Eastwood JB, Johnston A, Lee T, Holt DW: Pharmacokinetics of mycophenolate mofetil in patients with end-stage renal failure. Kidney Int 2000;57:1164-1168.

41 Hanada K, Ogawa R, Son K, Sasaki Y, Kikkawa A, Ichihara S, Ogata H: Effects of indoxylsulfate on the in vitro hepatic metabolism of various compounds using human liver microsomes and hepatocytes. Nephron Physiol 2006;103:p179-p186.

42 Sanchez Fructuoso AI, de la Higuera MA, Garcia-Ledesma P, Giorgi M, Ramos F, Calvo N, Perez-Flores I, Barrientos A: Graft outcome and mycophenolic acid trough level monitoring in kidney transplantation. Transplant Proc 2009;41:2102-2103.

$>43$ Borrows R, Chusney G, Loucaidou M, James A, Lee J, Tromp JV, Owen J, Cairns T, Griffith M, Hakim N, McLean A, Palmer A, Papalois V, Taube D: Mycophenolic acid 12-h trough level monitoring in renal transplantation: association with acute rejection and toxicity. Am J Transplant 2006;6:121-128.

44 Le Meur Y, Buchler M, Thierry A, Caillard S, Villemain F, Lavaud S, Etienne I, Westeel PF, Hurault de Ligny B, Rostaing L, Thervet E, Szelag JC, Rerolle JP, Rousseau A, Touchard G, Marquet P: Individualized mycophenolate mofetil dosing based on drug exposure significantly improves patient outcomes after renal transplantation. Am J Transplant 2007; 7:2496-2503.

45 van Gelder T, Silva HT, de Fijter JW, Budde K, Kuypers D, Tyden G, Lohmus A, Sommerer C, Hartmann A, Le Meur Y, Oellerich M, Holt DW, Tonshoff B, Keown P, Campbell S, Mamelok RD: Comparing mycophenolate mofetil regimens for de novo renal transplant recipients: the fixed-dose concentration-controlled trial. Transplantation 2008; 86:1043-1051.

46 Jeong H, Kaplan B: Therapeutic monitoring of mycophenolate mofetil. Clin J Am Soc Nephrol 2007;2:184-191.

47 van Gelder T: Mycophenolate blood level monitoring: recent progress. Am J Transplant 2009;9:1495-1499.

48 Neumann I, Haidinger M, Jager H, Grutzmacher H, Griesmacher A, Muller MM, Bayer PM, Meisl FT: Pharmacokinetics of mycophenolate mofetil in patients with autoimmune diseases compared renal transplant recipients. J Am Soc Nephrol 2003;14: 721-727.

49 Neumann I, Fuhrmann H, Fang IF, Jaeger A, Bayer P, Kovarik J: Association between mycophenolic acid 12-h trough levels and clinical endpoints in patients with autoimmune disease on mycophenolate mofetil. Nephrol Dial Transplant 2008;23:3514-3520. 
50 Schaier M, Scharpf D, Scholl C, Hug F, Schwenger V, Zeier MG: Pharmacodynamic drug monitoring a new tool for individualised immunosuppression in patients with ANCA-associated systemic vasculitis. Am Soc Nephrol Abstracts. J Am Soc Nephrol 2009;20(suppl):F-PO1300.

- $51 \mathrm{Hu}$ W, Liu C, Xie H, Chen H, Liu Z, Li L: Mycophenolate mofetil versus cyclophosphamide for inducing remission of ANCA vasculitis with moderate renal involvement. Nephrol Dial Transplant 2008;23:13071312 .

-52 de Groot K, Harper L, Jayne DR, Flores Suarez LF, Gregorini G, Gross WL, Luqmani R, Pusey CD, Rasmussen N, Sinico RA, Tesar V, Vanhille P, Westman K, Savage CO: Pulse versus daily oral cyclophosphamide for induction of remission in antineutrophil cytoplasmic antibody-associated vasculitis: a randomized trial. Ann Intern Med 2009; 150: 670-680.

-53 Jayne D, Rasmussen N, Andrassy K, Bacon P, Tervaert JW, Dadoniene J, Ekstrand A, Gaskin G, Gregorini G, de Groot K, Gross W, Hagen EC, Mirapeix E, Pettersson E, Siegert C, Sinico A, Tesar V, Westman K, Pusey C: A randomized trial of maintenance therapy for vasculitis associated with antineutrophil cytoplasmic autoantibodies. N Engl J Med 2003;349:36-44.

-54 Stassen PM, Cohen Tervaert JW, Stegeman CA: Induction of remission in active antineutrophil cytoplasmic antibody-associated vasculitis with mycophenolate mofetil in patients who cannot be treated with cyclophosphamide. Ann Rheum Dis 2007;66:798-802.

- 55 Joy MS, Hogan SL, Jennette JC, Falk RJ, Nachman PH: A pilot study using mycophenolate mofetil in relapsing or resistant ANCA small vessel vasculitis. Nephrol Dial Transplant 2005;20:2725-2732.

56 Nowack R, Gobel U, Klooker P, Hergesell O, Andrassy K, Van der Woude F: Mycophenolate mofetil for maintenance therapy of Wegener's granulomatosis and microscopic polyangiitis: a pilot study in 11 patients with renal involvement. J Am Soc Nephrol 1999; 10:1965-1971.

57 Kazderova M, Jancova E, Rysava R, Merta M, Tesar V: Mycophenolate mofetil in low doses stabilizes and improves antineutrophil cytoplasmic antibody-associated vasculitis and lupus nephritis. Arch Med Res 2008;39:115119.

-58 Koukoulaki M, Jayne DR: Mycophenolate mofetil in anti-neutrophil cytoplasm antibodies-associated systemic vasculitis. Nephron Clin Pract 2006;102:c100-c107.
59 Langford CA, Talar-Williams C, Sneller MC: Mycophenolate mofetil for remission maintenance in the treatment of Wegener's granulomatosis. Arthritis Rheum 2004;51:278283.

60 Assaf C, Mewis G, Orfanos CE, Geilen CC Churg-Strauss syndrome: successful treatment with mycophenolate mofetil. Br J Dermatol 2004;150:598-600.

61 Hoffman GS, Ahmed AE: Surrogate markers of disease activity in patients with Takayasu arteritis. A preliminary report from the International Network for the Study of the Systemic Vasculitides (INSSYS). Int J Cardiol 1998;66:S191-S194.

62 Kerr GS, Hallahan CW, Giordano J, Leavitt RY, Fauci AS, Rottem M, Hoffman GS: Takayasu arteritis. Ann Intern Med 1994; 120:919-929.

63 Daina E, Schieppati A, Remuzzi G: Mycophenolate mofetil for the treatment of takayasu arteritis: report of three cases. Ann Intern Med 1999;130:422-426.

64 Shinjo SK, Pereira RM, Tizziani VA, Radu AS, Levy-Neto M: Mycophenolate mofetil reduces disease activity and steroid dosage in Takayasu arteritis. Clin Rheumatol 2007;26: 1871-1875.

65 Worm M, Sterry W, Kolde G: Mycophenolate mofetil is effective for maintenance therapy of hypocomplementaemic urticarial vasculitis. Br J Dermatol 2000;143:1324.

-66 Taverna JA, Radfar A, Pentland A, Poggioli G, Demierre MF: Case reports: nodular vasculitis responsive to mycophenolate mofetil. J Drugs Dermatol 2006;5:992-993.

67 Gladstone DE, Golightly MG, Zamkoff KW: Severe, refractory type ii essential mixed cryoglobulinemia treated with 2-chlorodeoxyadenosine and mycophenolate mofetil Rheumatol Int 2005;25:635-636.

-68 Adler YD, Mansmann U, Zouboulis CC: Mycophenolate mofetil is ineffective in the treatment of mucocutaneous Adamantiades-Behçet's disease. Dermatology 2001; 203:322-324.

69 Ostensen M, Khamashta M, Lockshin M, Parke A, Brucato A, Carp H, Doria A, Rai R, Meroni P, Cetin I, Derksen R, Branch W, Motta M, Gordon C, Ruiz-Irastorza G, Spinillo A, Friedman D, Cimaz R, Czeizel A, Piette JC, Cervera R, Levy RA, Clementi M, De Carolis S, Petri M, Shoenfeld Y, Faden D, Valesini G, Tincani A: Anti-inflammatory and immunosuppressive drugs and reproduction. Arthritis Res Ther 2006;8:209.

70 Sifontis NM, Coscia LA, Constantinescu S, Lavelanet AF, Moritz MJ, Armenti VT: Pregnancy outcomes in solid organ transplant recipients with exposure to mycophenolate mofetil or sirolimus. Transplantation 2006 82:1698-1702.

71 El Sebaaly Z, Charpentier B, Snanoudj R: Fetal malformations associated with mycophenolate mofetil for lupus nephritis. Nephrol Dial Transplant 2007;22:2722.
72 Schoner K, Steinhard J, Figiel J, Rehder H: Severe facial clefts in acrofacial dysostosis: a consequence of prenatal exposure to mycophenolate mofetil? Obstet Gynecol 2008;111: 483-486.

73 Perez-Aytes A, Ledo A, Boso V, Saenz P, Roma E, Poveda JL, Vento M: In utero exposure to mycophenolate mofetil: a characteristic phenotype? Am J Med Genet 2008; 146A:1-7.

74 Jungraithmayr T, Staskewitz A, Kirste G, Boswald M, Bulla M, Burghard R, Dippell J, Greiner C, Helmchen U, Klare B, Klaus G, Leichter HE, Mihatsch MJ, Michalk DV, Misselwitz J, Plank C, Querfeld U, Weber LT, Wiesel M, Tonshoff B, Zimmerhackl LB: Pediatric renal transplantation with mycophenolate mofetil-based immunosuppression without induction: results after three years. Transplantation 2003;75:454-461.

75 Morath C, Schwenger V, Beimler J, Mehrabi A, Schmidt J, Zeier M, Muranyi W: Antifibrotic actions of mycophenolic acid. Clin Transplant 2006;20(suppl 17):25-29.

76 Copeland JW, Beaumont BW, Merrilees MJ, Pilmore HL: Epithelial-to-mesenchymal transition of human proximal tubular epithelial cells: effects of rapamycin, mycophenolate, cyclosporin, azathioprine, and methylprednisolone. Transplantation 2007; 83:809-814.

77 Nankivell BJ, Wavamunno MD, Borrows RJ, Vitalone M, Fung CL, Allen RD, Chapman JR, O'Connell PJ: Mycophenolate mofetil is associated with altered expression of chronic renal transplant histology. Am J Transplant 2007;7:366-376.

78 Mukhtyar C, Guillevin L, Cid MC, Dasgupta B, de Groot K, Gross W, Hauser T, Hellmich B, Jayne D, Kallenberg CG, Merkel PA, Raspe $\mathrm{H}$, Salvarani C, Scott DG, Stegeman C, Watts R, Westman K, Witter J, Yazici H, Luqmani R: EULAR recommendations for the management of primary small and medium vessel vasculitis. Ann Rheum Dis 2009;68:310317.

79 Stepkowski SM: Molecular targets for existing and novel immunosuppressive drugs. Expert Rev Mol Med 2000;2:1-23.

80 Yalcindag FN, Amer R, Forrester JV: Mycophenolate mofetil in the treatment of ocular inflammation in ANCA-associated vasculitis. J Ocul Pharmacol Ther 2008;24:249-254.

$\rightarrow 81$ Iatrou C, Zerbala S, Revela I, Spanou E, Marinaki S, Nakopoulou L, Boletis J: Mycophenolate mofetil as maintenance therapy in patients with vasculitis and renal involvement. Clin Nephrol 2009;72:31-37. 


\section{Editorial Comment}

Richard J. Glassock, Laguna Niguel

The salts of mycophenolic acid (mycophenolate mofetil, MMF, and mycophenolate sodium) could justifiably be called the signature immunosuppressive drugs of the first decade of the 21 st century. In a scholarly minireview, Hiemstra, Jones and Jayne of the renowned Lupus and Vasculitis Unit of Addenbrookes Hospital and Cambridge University focus on recent developments in the utilization of these drugs (predominantly MMF) in systemic vasculitis associated with antineutrophil cytoplasmic autoantibodies (ANCA+ vasculitis). While the toxicity profile of MMF favors its use over cyclophosphamide for induction of remissions in ANCA+ small vessel vas- culitis, we still remain uncertain over comparative efficacy - a situation that will hopefully be remedied by the MYCYC trial in progress. Maintenance of remission in ANCA+ vasculitis by MMF is encouraging, but side effects and a high relapse rate may limit its utility. The IMPROVE trial should settle the remaining issues in 2010. The role of monitoring blood levels of mycophenolic acid continues to be very uncertain. Hiemstra et al. have been properly cautious in their conclusions that mycophenolates (primarily MMF) have not yet achieved the status as a first-line treatment regimen for ANCA+ vasculitis. 